(C) 2013 IEEE. Personal use of this material is permitted. Permission from IEEE must be obtained for all other uses, in any current or future media, including reprinting/republishing this material for advertising or promotional purposes, creating new collective works, for resale or redistribution to servers or lists, or reuse of any copyrighted component of this work in other works.

Digital Object Identifier (DOI): (to be appear)

Proceedings of the IEEE Energy Conversion Congress and Exposition (ECCE 2013), Denver, CO, USA, 14-19 September, 2013.

\title{
Real Filed Mission Profile Oriented Design of a SiC-Based PV-Inverter Application
}

Nicolae-Christian Sintamarean

Frede Blaabjerg

Huai Wang

\section{Suggested Citation}

N. C. Sintamarean, F. Blaabjerg, and H. Wang, "Real filed mission profile oriented design of a SiCbased PV-inverter application," in Proc. IEEE Energy Convers. Congr. and Expo., 2013, pp. 940-947. 


\title{
Real Field Mission Profile Oriented Design of a SiC-Based PV-Inverter application
}

\author{
C. Sintamarean, F. Blaabjerg, H. Wang, Y. Yang \\ Department of Energy Technology, Center of Reliable Power Electronics \\ Aalborg University \\ Aalborg, Denmark \\ ncs@et.aau.dk,fbl@et.aau.dk,hwa@et.aau.dk,yoy@et.aau.dk
}

\begin{abstract}
This paper introduces a real field mission profile oriented design tool for the new generation of grid connected PVinverters applications based on SiC-devices. The proposed design tool consists of a grid connected PV-inverter model, an ElectroThermal model, a converter safe operating area (SOA) model, a mission profile model and an the evaluation block. The PVsystem model involves a three level bipolar switch neutral point clamped (3L-BS NPC) inverter connected to the three phase grid through a LCL-filter. Moreover, the SOA model calculates the required converter heatsink thermal impedance $Z_{\text {th_H }}$ in order to perform in a safe mode for the whole operating range. Furthermore, the proposed design tool considers the mission profile (the measured solar irradiance and ambient temperature) from the real field where the converter will operate. Thus, a realistic loading of the converter devices is achieved. To consider one year real field measurements of the mission profile, an accurate long term simulation model is developed. The model predicts the junction and case temperature of the converter devices, for three different case scenarios. In the first case, a one year mission profile is used into the model with a sampling rate of five minutes. For the second and third case, a more detailed analysis is performed for one week mission profile (in the wintersummer time) with a sampling rate of $25 \mathrm{~s}$. The simulation results shows the thermal loading distribution among the converter devices (MOSFET, IGBT+FD) in terms of junction (average, peak, $\Delta T$ ) and case (average) temperature for all three simulation cases. Finally, the evaluation block is used to analyze the results in order to perform a thermal loading-based classification of the converter devices.
\end{abstract}

Keywords-mission profile; PV-inverters; design tool; thermal loading; SiC-devices

\section{INTRODUCTION}

The improvement of power electronic systems is directly related with the evolution of power semiconductor devices. Nowadays, the power devices requirements include higher blocking voltages, higher switching frequency, higher efficiency, higher power density, higher reliability and lower cost. In order to achieve this goal, the development of power electronics devices based on Wide Band-Gap (WBG) semiconductors, like Silicon Carbide $(\mathrm{SiC})$ and gallium nitride $(\mathrm{GaN})$, are interesting. These WBG devices have superior electrical properties and are likely candidates to replace $\mathrm{Si}$ in some applications [1], [2]. Their recent commercialization is expected to revolutionize the power electronics industry in the near future. The integration on the actual commercial market [2] of the WBG-semiconductor based devices is emphasized with red dotted line in Fig.1. It is worth to mention that, according to their rated power (available on the market today), the main applications that can be covered by this field are PV inverters, adjustable speed drives, small pumps and automotive. Moreover, PV-inverter companies already started to produce converters based on these devices (ex: SMA with STP 20000TLHE-10, REFUsol with 020K-SCI) [3][4].

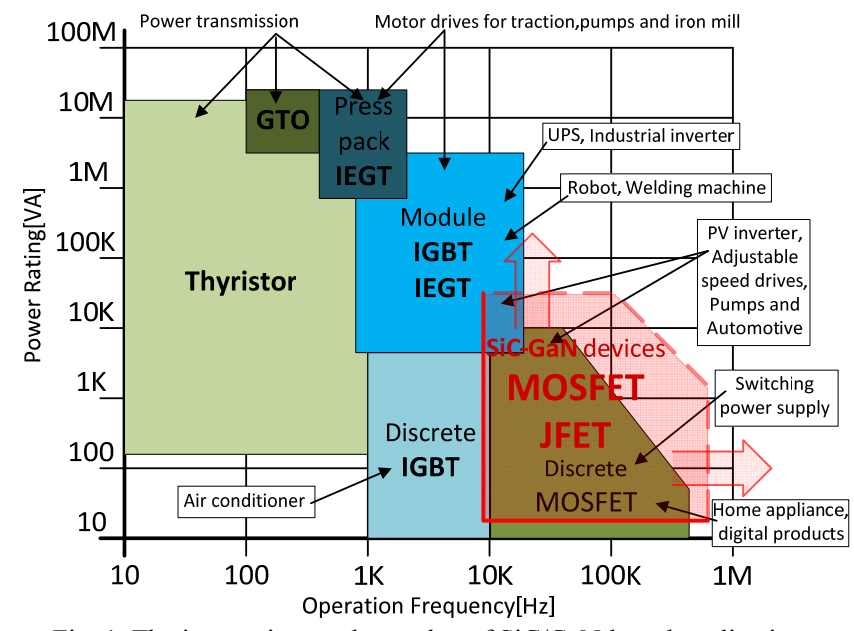

Fig. 1. The integration on the market of $\mathrm{SiC} / \mathrm{GaN}$-based applications

The converter availability in PV-systems application is the most important aspect and it depends on the component reliability, efficiency and its maintenance [5], [6]. Therefore, highly reliable components are required in order to minimize the downtime during the lifetime of the converter and implicitly the maintenance costs [7], [8]. From Fig. 2(a) [9] can be seen the main source of stressors distribution which involves failure, where the temperature is the most important parameter. Due to these causes the failure rate sharing of the main components used in a power converter design has the distribution according to Fig. 2(b) [10]. It is worth to mention that semiconductor devices, capacitors and PCBs are the most prone to failure within the converter components [6], [11], [12]. Therefore, the maximum electrical ratings and the thermal limitations of the semiconductor devices plays a key role in the robustness design and reliability of power electronics converters [11], [13]. The producers should guarantee that under all mentioned operating conditions, the case and junction temperature of all devices do not exceed their designed physical limits, otherwise it may involve failures of the product [14]. This problem has a higher impact 
for the new generation of power converters, which are based on WBG-devices, due to their superior Electro-Thermal properties which involves a higher temperature operating point compared to the Si-based devices [2], [15]. Therefore, it is important to perform a thermal loading analysis of the converter in order to determine if the devices are performing within the maximum allowed physical limits, especially in the worst case scenario.

This paper deals with a real field mission profile oriented design for the new generation of grid connected PV-inverters applications. Moreover, the proposed design tool considers the mission profile (one year measured solar irradiance and ambient temperature) of the real field where the converter will perform. It is important to have a deeper understanding of the thermal repartition among the devices according with a real field load in order to see if the converter is performing in the safe operating area range during the whole year operation. Finally, the thermal loading difference within the devices will also have a negative impact in the converter reliability.

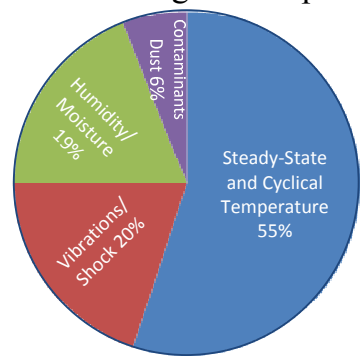

(a)Source of stress distribution [9]

Fig. 2. Stress causes and failure distribution in power electronic systems

\section{Mission Profile Oriented Design}

This paper introduces a real field mission profile oriented design for the new generation of grid connected PV-inverters applications. According with Fig. 3, the proposed design tool consists of a mission profile model, a grid connected PVinverter model, an Electro-Thermal model, the converter safe operating area (SOA) model and the evaluation block.

The involved parameters emphasized in Fig. 3 are as follows: SIRR - solar irradiance, Ta - ambient temperature, $\mathrm{I}_{\mathrm{MD}^{-}}$ MOSFET freewheeling diode current, $\mathrm{I}_{\mathrm{M}}$ - MOSFET drain current, $\mathrm{V}_{\mathrm{DC}}$ - voltage across the device in the off state, $\mathrm{F}_{\mathrm{Sw}^{-}}$ switching frequency of the device, $\mathrm{Z}_{\mathrm{th} \_\mathrm{H}}-$ heatsink thermal impedance, $T_{J_{-} \text {peak }}$ - junction temperature peak value, $T_{J_{-} \text {avarage }}{ }^{-}$ junction temperature average value, $T_{C}$ - case temperature of the device.

The proposed design tool estimates the load current of the converter due to the real field mission profile applied as an input to the model. Moreover, the thermal loading distribution across the converter devices (MOSFET, IGBT+FD) in terms of junction (average, peak, $\Delta \mathrm{T}$ ) and case (average) temperature is also predicted.

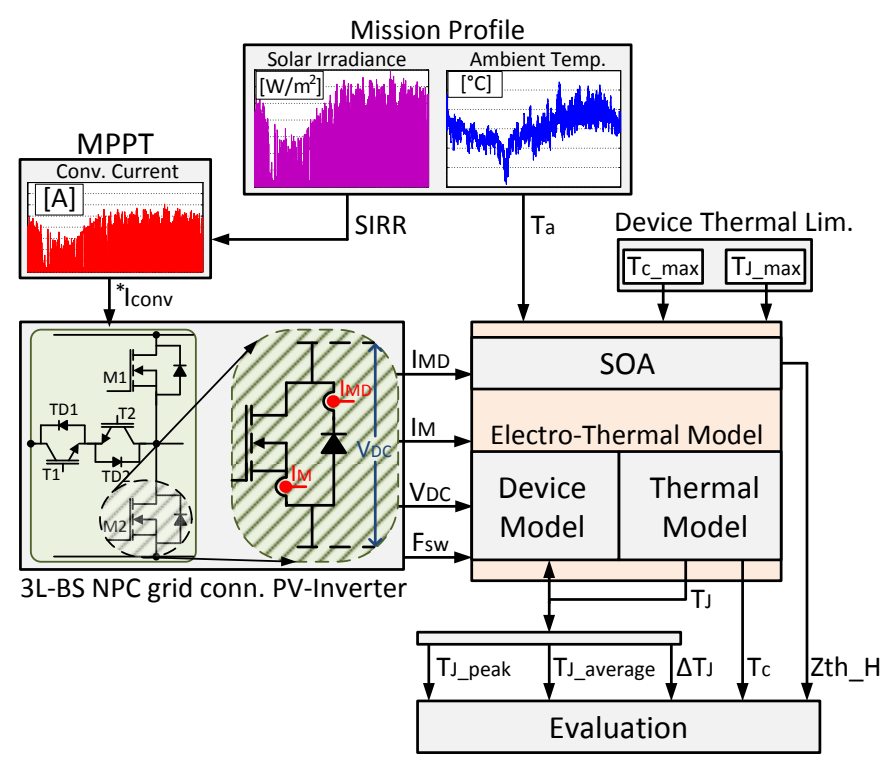

Fig. 3. Proposed real field mission profile oriented design structure for the new generation of grid connected PV-inverters

\section{A. Real Field Mission Profille Model}

The proposed design tool presented in Fig. 3 considers the Mission Profile of the field where the converter will perform. The mission profile model is developed based on one year measured irradiance and ambient temperature at Aalborg University (Denmark) from October 2011 to September 2012 (Fig. 9 a). The sampling frequency of the measured data is $5 \mathrm{~Hz}$. Thus a more realistic loading of the converter devices can be achieved.

\section{B. Grid Connected PV-inverter Design}

Power electronics technology plays a key role in grid connected PV-systems development. Various converter configurations are available, but this study focus on one of the most efficient three-phase PV-inverter topologies used nowadays in industry 3L-BS NPC [4]. The proposed PVsystem, depicted in Fig. 4, consists of a 3L-BS NPC inverter connected to the three phase grid through a passive LCL-filter (in order to mitigate the switching frequency harmonics). Fig. 4 introduces the main control blocks which are used to achieve the desired converter functionalities. A more detailed description of the control design for a grid connected PVinverter has been presented in [16].

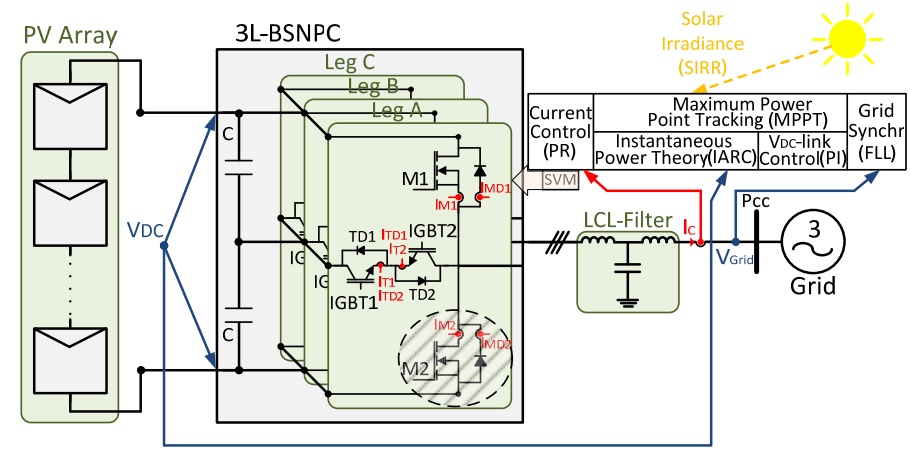

Fig. 4. Three phase grid connected 3L-BS NPC PV-inverter application 
The design of a $12 \mathrm{kVA}$ grid connected converter will be performed in agreement with the power rating parameters emphasized in Table I. According to the DC-link voltage $(1 \mathrm{kV})$ and the converter nominal output current (18 A RMS) the chosen devices for 3L-BS NPC topology (Fig. 4) have to fulfill the following requirements: to withstand full $\mathrm{V}_{\mathrm{DC}}$, to conduct the rated current and to operate in the higher switching frequency range. SiC MOSFETs from CREE satisfy these performances and are used for switches M1 and M2 (Fig.4). The connection to the middle-point 0 requires two switches as a consequence, the voltage stress is shared between them. Moreover, these devices should perform in low switching frequency range. Considering also the converter costs, the IGBTs from Infineon are suitable for this case. Considering the converter ratings, a LCL-filter design has also been performed according with [16] and the calculated values are listed in Table I.

TABLE I. CONVERTER DESIGN RAITINGS

\begin{tabular}{|c|c|c|c|}
\hline \multicolumn{4}{|c|}{ 3L-D/BS NPC PV-inverter Specifications } \\
\hline \multicolumn{2}{|l|}{ Rated power } & \multicolumn{2}{|c|}{$\mathrm{S}=12 \mathrm{kVA}$} \\
\hline \multicolumn{2}{|c|}{ Conv. Output phase voltage (RMS) } & \multicolumn{2}{|c|}{$\mathrm{V}_{\mathrm{N}}=230 \mathrm{~V}(\mathrm{RMS})(325 \mathrm{~V}$ peak $)$} \\
\hline \multicolumn{2}{|c|}{ Max. Output current (RMS) } & \multicolumn{2}{|c|}{$\mathrm{I}_{\max }=18 \mathrm{~A}(\mathrm{RMS})(25 \mathrm{~A}$ peak $)$} \\
\hline \multicolumn{2}{|l|}{ Max. DC-link Voltage } & \multicolumn{2}{|c|}{$\mathrm{V}_{\text {DC-max }}=1000 \mathrm{~V}$} \\
\hline \multicolumn{2}{|l|}{ Switching Frequency } & \multicolumn{2}{|c|}{$\mathrm{F}_{\mathrm{sw}}=48 \mathrm{kHz}$} \\
\hline \multicolumn{4}{|c|}{ Device Power Ratings } \\
\hline Device & $\begin{array}{l}\text { IGBT-Infineon } \\
\text { SKW30N60HS }\end{array}$ & $\begin{array}{c}\text { MOSFET-CREE } \\
\text { CMF20120D }\end{array}$ & $\begin{array}{l}\text { Diode-CREE } \\
\text { C4D20120A }\end{array}$ \\
\hline Break-Down Voltage & $\mathrm{V}_{(\mathrm{BR}) \mathrm{CE}}=600 \mathrm{~V}$ & $\mathrm{~V}_{(\mathrm{BR}) \mathrm{DS}}=1200 \mathrm{~V}$ & $V_{R}=1200 \mathrm{~V}$ \\
\hline Max allowed. J/C & $\mathrm{T}_{\mathrm{J}}=135^{\circ} \mathrm{C}$ & \multirow{2}{*}{$\begin{aligned} \mathrm{T}_{\mathrm{J}} & =135^{\circ} \mathrm{C} \\
\mathrm{T}_{\mathrm{C}} & =100^{\circ} \mathrm{C}\end{aligned}$} & $\mathrm{T}_{\mathrm{J}}=175^{\circ} \mathrm{C}$ \\
\hline Temperature & $\mathrm{T}_{\mathrm{C}}=100^{\circ} \mathrm{C}$ & & $\mathrm{T}_{\mathrm{C}}=135^{\circ} \mathrm{C}$ \\
\hline \multicolumn{4}{|c|}{ LCL-Filter Parameters } \\
\hline Converter Side & \multicolumn{2}{|c|}{$\mathrm{L}_{\mathrm{C}}=0.175 \mathrm{mH}$} & $=7 \mathrm{~m} \Omega$ \\
\hline Grid side & $\mathrm{L}_{\mathrm{g}}=0.075 \mathrm{mH}$ & \multicolumn{2}{|c|}{$\mathrm{R}_{\mathrm{g}}=3 \mathrm{~m} \Omega$} \\
\hline Filter capacitor & $\mathrm{C}_{\mathrm{f}}=0.5 \mu \mathrm{F}$ & \multicolumn{2}{|c|}{$\mathrm{R}_{\mathrm{f}}=10 \mathrm{k} \Omega$} \\
\hline
\end{tabular}

\section{Electro-Thermal Model Design}

The proposed model aims to estimate the junction and case temperature for the new generation of power electronics devices. Moreover, the model considers the thermal coupling within the transistor (MOSFET, IGBT) and its freewheeling diode, integrated into the same package. The influence of the ambient temperature variation is also included.

The input signals in the model are: the device current $\left(\mathrm{I}_{\mathrm{D}}\right)$, the DC-link voltage of the converter $\left(\mathrm{V}_{\mathrm{DC}}\right)$, the switching frequency $\mathrm{f}_{\mathrm{SW}}$ and the ambient temperature $\left(\mathrm{T}_{\mathrm{a}}\right)$. According with Fig. 5, three types of models are involved in the electrothermal analysis: the device model, the power loss model and the thermal model.

The Device-Model estimates the voltage drop across the device, the leakage current and the switching energies as a function of the current, the off-state blocking voltage and junction temperature. Furthermore, the estimated parameters and the switching frequency will be used into the $\mathrm{P}_{\text {Loss }}$ Model where, the instantaneous conduction, blocking/leakage and switching losses of the device are calculated. Moreover, the total losses $\left(\mathrm{P}_{\text {tot loss }}\right)$ and the ambient temperature $\left(\mathrm{T}_{\mathrm{a}}\right)$ are feed into the thermal model which estimates the device case temperature $\left(T_{c}\right)$ and the junction temperature $\left(T_{j}\right)$. Finally, by providing the junction temperature as a feedback to the device model, the temperature impact in the losses is also considered.
The junction and case temperature estimation of devices mentioned in Table I (MOSFET, IGBT and Diode) has been performed by implementing the proposed Electro-Thermal Model according with [17].

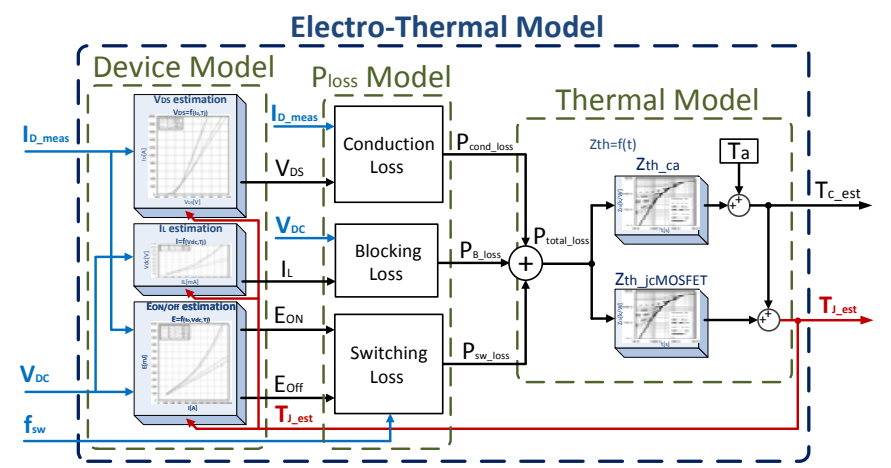

Fig. 5. Proposed Electro-Thermal model structure for device junction and case temperature estimation

\section{Converter Safe Operating Area (SOA)}

Fig. 6 presents the safe operating area (SOA) of the three phase 3L-BS NPC PV-inverter for grid connected application by considering the maximum allowed converter current, according to the switching frequency operation and thermal impedance value of the heatsink.

It is worth to mention that the converter is performing within the safe operating area range if the thermal limitations of the power electronics devices (SiC MOSFET, IGBT+FD) are not exceeded (Table I).

Therefore, the SOA of each device is analyzed during the converter operation according with the approach shown in [16]. The converter SOA limits are determined considering the following parameters provided as model input: the converter current $\mathrm{I}_{\mathrm{C}}$, the DC-link voltage $\mathrm{V}_{\mathrm{DC}}=1 \mathrm{kV}$, the power factor $\cos \varphi=1$ (active power injection), the operating switching frequency $\mathrm{f}_{\mathrm{sw}}$ (of the MOSFET devices) varies from $10 \mathrm{kHz}$ to $100 \mathrm{kHz}$ according with the study case, the ambient temperature is constant at $\mathrm{T}_{\mathrm{a}}=40^{\circ} \mathrm{C}$, and the thermal limitations of the devices in terms of junction and case temperature $\left(\max . \mathrm{T}_{\mathrm{j}}=135^{\circ} \mathrm{C}\right.$ and $\left.\mathrm{T}_{\mathrm{c}}=100^{\circ} \mathrm{C}\right)$.

Finally, this model calculates the maximum allowed converter heatsink thermal impedance $\mathrm{Z}_{\mathrm{th}} \mathrm{H}$ in order to perform within the SOA for the whole operating range. For example in the studied case, the converter maximum operating point corresponds to a peak current of $25 \mathrm{~A}$ and an operating switching frequency of $50 \mathrm{kHz}$. According with Fig. 6, in order to perform in a safe way at this operating point a maximum heatsink thermal impedance of $\mathrm{Z}_{\mathrm{th}}=1 \mathrm{~K} / \mathrm{W}$ is required.

If the application demands a higher current for the same switching frequency (e.g. $30 \mathrm{~A}$ for $50 \mathrm{kHz}$ ) or a higher switching frequency for the same current (e.g. $80 \mathrm{kHz}$ for 25 A) the thermal impedance of the heatsink has to be recalculated (decreased to $\mathrm{Zth}=0.7 \mathrm{~K} / \mathrm{W}$ ), otherwise the physical thermal limitations of the devices are exceeded. 


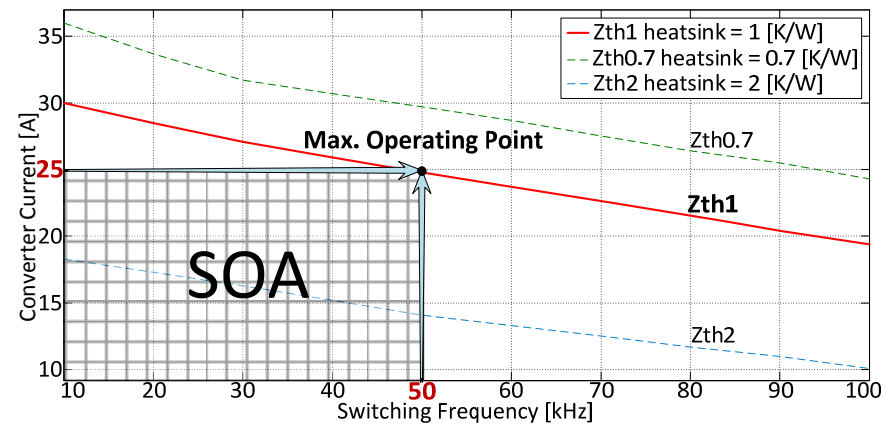

Fig. 6. Safe operating area (SOA) of the three phase 3L-BS NPC PV-inverter for grid connected application by considering the maximum allowed converter current, according with the switching frequency operation and the heatsink thermal impedance value-variation

\section{E. Long Term Simulation Model}

Thermal loading distribution across the converter devices is estimated by implementing a detailed simulation model in Matlab/Simulink, considering the above mentioned specifications. The proposed model consists of two main parts. First part deals with the modeling of a three phase grid connected 3L-BS NPC PV-inverter application. The second part deals with the implementation of the proposed ElectroThermal Model by including also the heatsink thermal impedance $\mathrm{Z}_{\mathrm{th} \_\mathrm{H}}$ determined in the above section.

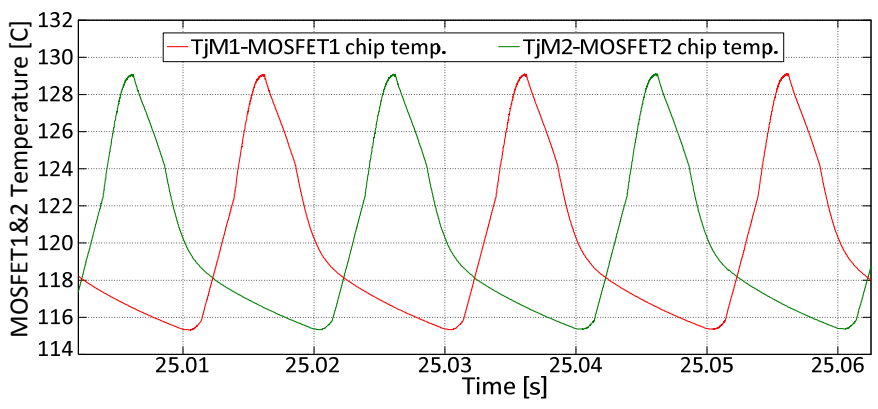

(a) MOSFET1\&2 thermal cycling

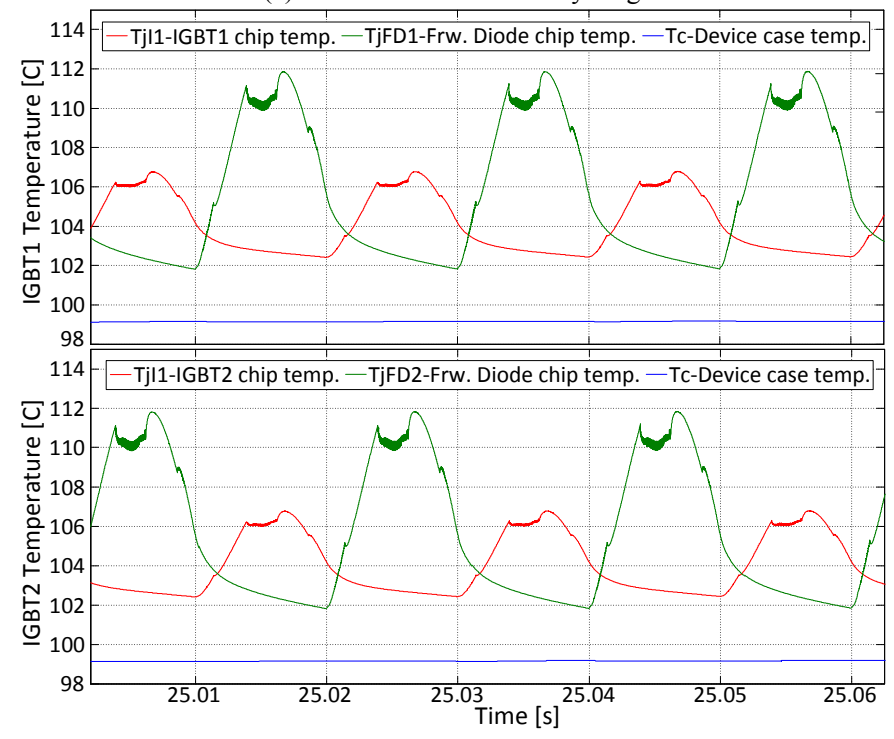

(b) IGBT1\&2 and its freewheeling diode thermal cycling

Fig. 7. Thermal loading estimation of the 3L-BSNPC PV-inverter devices
Fig. 7 shows the thermal loading distribution across the converter devices for the worst case scenario respectively when the rated active power $(12 \mathrm{~kW})$ is injected into the grid. Moreover, the MOSFET1/2 thermal cycling is presented in Fig. 7 (a). For the IGBT1/2 it is plotted also its freewheeling Diode $1 / 2$ temperature (Fig. 7(b)). For this topology the current stress of the neutral point clamping IGBT is the same with the freewheeling diode (Fig. 4). Even if they have the same current stress, the temperature of IGBT and diode differs considerably due to the thermal impedance, which is double in the case of diode. Finally, the thermal loading difference within the devices will have a negative impact on the converter reliability. Therefore, it is important to have a deep understanding of the thermal repartition on the converter devices according with a real field load.

In order to consider the one year real field measurements of the mission profile (irradiance and ambient temperature) an accurate Long Term Simulation Model (LTSM) is required.

For this purpose, a model based on the results obtained with the Detailed Simulation Model (DSM) for different operating conditions is proposed. Moreover, the model validation and its accuracy are achieved by performing a comparison study with the DSM (Fig. 8).

The model estimates the device: average, peak and $\Delta \mathrm{T}$ of the junction temperature and the average of the case temperature.

In Fig. 8 is emphasized the thermal loading transient behavior/study of the converter devices (MOSFET, IGBT+FD) when the 3L-BS NPC injected power is changed from $0 \mathrm{~kW}$ to $12 \mathrm{~kW}$ (25 A peak) at time 0 s and from $12 \mathrm{~kW}$ to $7.3 \mathrm{~kW}$ (15A peak) at time $25 \mathrm{~s}$. The thermal loading transient response is influenced by the heatsink time constant. According to the simulation results shown in Fig. 8, it is worth to mention that the time required for the device temperature to achieve the steady state value for the worst case scenario, (when a step from 0 to $12 \mathrm{~kW}$ is applied) is around $25 \mathrm{~s}$. Therefore, in order to consider the heatsink time response, the average value of the irradiance for each $25 \mathrm{~s}$ interval (should be considered) should be provided as an input to the model.

Fig. 8 shows the temperature obtained with the detailed simulation model (instantaneous $\mathrm{Tj}$ and $\mathrm{Tc}$ ) for the devices used in 3L-BS NPC inverter (MOSFET, IGBT+FD). Moreover on the same plot are shown the temperature signals obtained with the long term simulation model (average, peak and $\Delta \mathrm{T}$ of the junction temperature and the average of the case temperature).

Comparing the obtained results (DSM vs. LTSM) it is worth to mention that the LTSM model performs an accurate estimation of the thermal loading. The error of the LTSM is very small $(<2 \%)$ when comparing with DSM for all three simulated cases. Based on these observations, the proposed LTSM model has been validated and will be further used to perform the thermal loading estimation of the converter devices for a one year mission profile. 


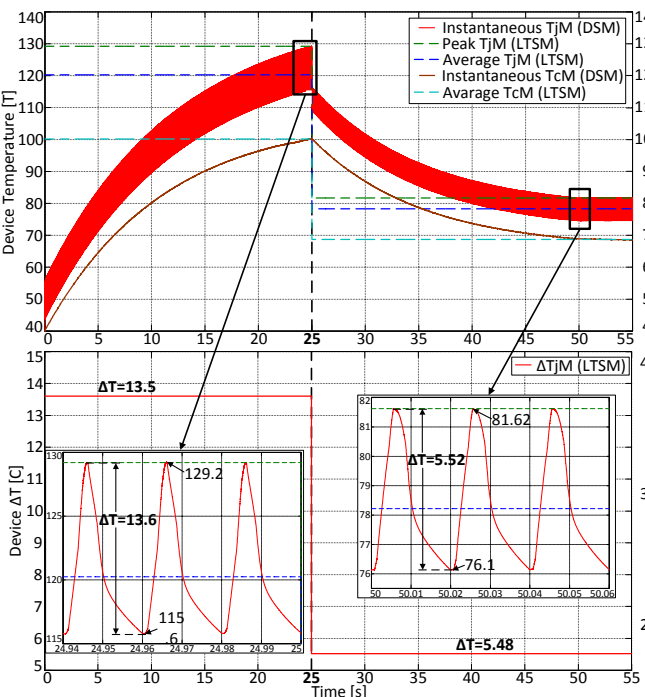

(a) MOSFET Cycling estimation

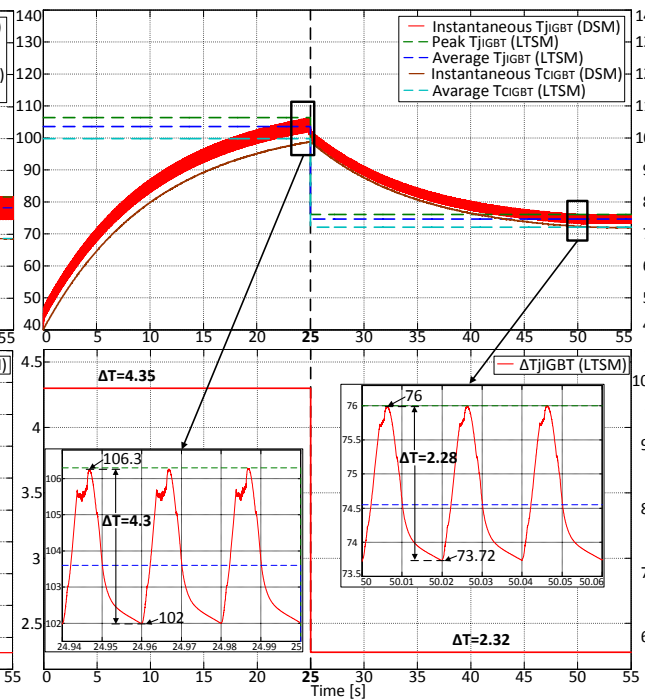

(b) IGBT cycling estimation

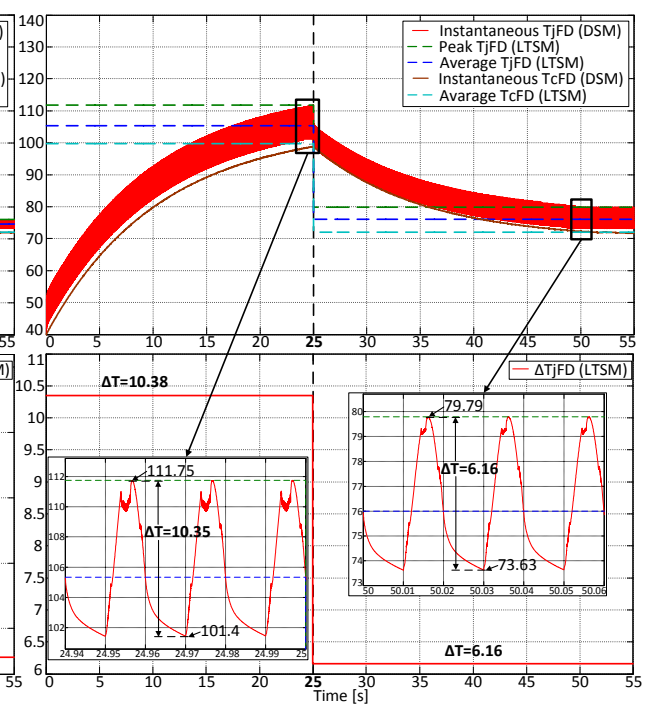

(c) IGBT Freewheeling diode cycling estimation

Fig. 8. Validation of the Long Term Simulation Model (LTSM) by comparing the obtained results with the Detailed Simulation Model (DSM)

\section{Simulation Results}

In order to consider a one year real field measurements of the mission profile (irradiance and ambient temperature) an accurate long term simulation model is used.

The model has been validated in the previous section, and will be further used to perform the thermal loading estimation of the converter devices for one year mission profile.

The proposed design tool considers the Mission Profile of the real field where the converter will perform. The mission profile model is developed based on one year measured solar irradiance and ambient temperature at Aalborg University (Denmark) from October 2011 to September 2012. Thus a more realistic loading of the converter devices is achieved. The sampling frequency of the measured data is $5 \mathrm{~Hz}$.

According to the obtained simulation results shown in Fig. 8 it is worth to mention that the time required for the device temperature to achieve the steady state value, for the worst case scenario, (when a step from 0 to $12 \mathrm{~kW}$ is applied) is around $25 \mathrm{~s}$. Therefore, in order to consider the heatsink time response, the average value of the irradiance for each $25 \mathrm{~s}$ interval is provided as an input to the model.

The long term simulation is done for the three case scenarios. In the first case a one year mission profile is used with a sampling rate of 5 minutes (Fig. 9 (a)). For the second and third case a more detailed analyses is performed for one week mission profile (simulation) with a sampling rate of $25 \mathrm{~s}$ (for the coldest week in the winter Fig. 9 (b) and the hottest week in the summer Fig. 9 (c)).

The obtained simulation results presents in Fig. 9 the load current of the converter due to the real field mission profile applied as an input to the model for all three cases. Moreover, Fig. 10 shows the thermal loading distribution across the converter devices (MOSFET, IGBT+FD) in terms of junction (average, peak and $\Delta \mathrm{T}$ ) and case (average) temperature for all three simulation cases. According to the obtained results it can be stated that the thermal limitations of the devices are not exceeded. 

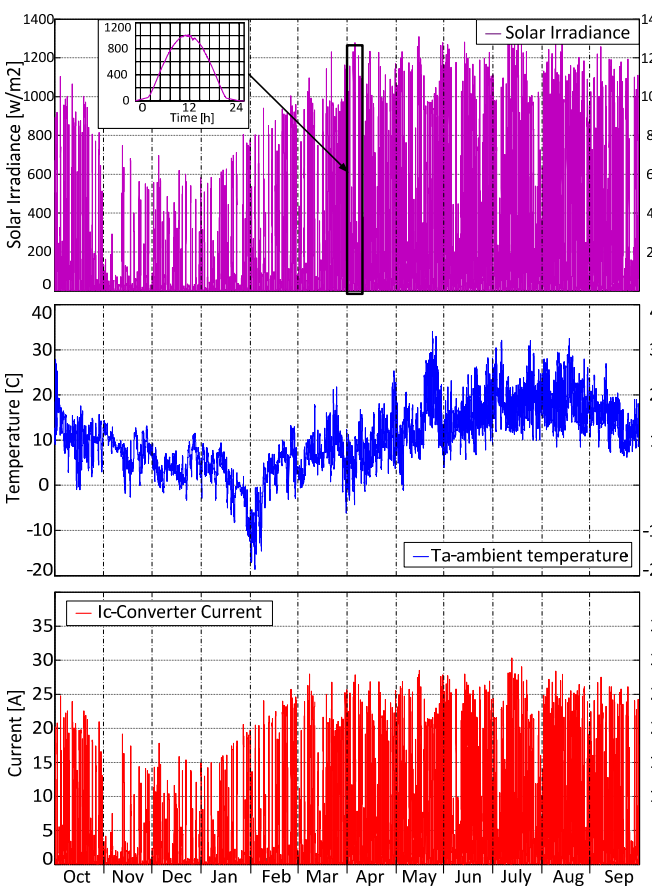

(a) One year mission profile and the corresponding converter current
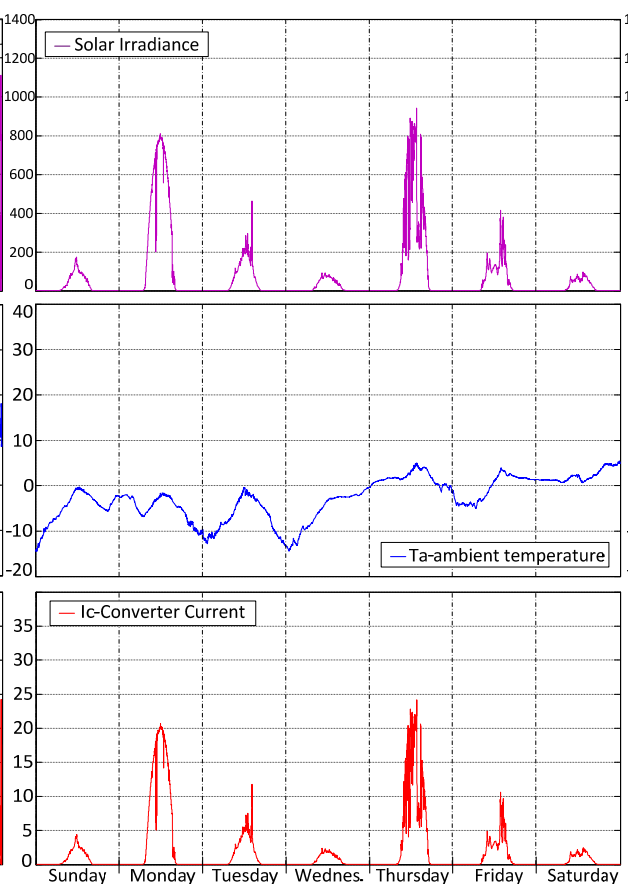

(b) One week mission profile during the winter time and the corresponding converter current
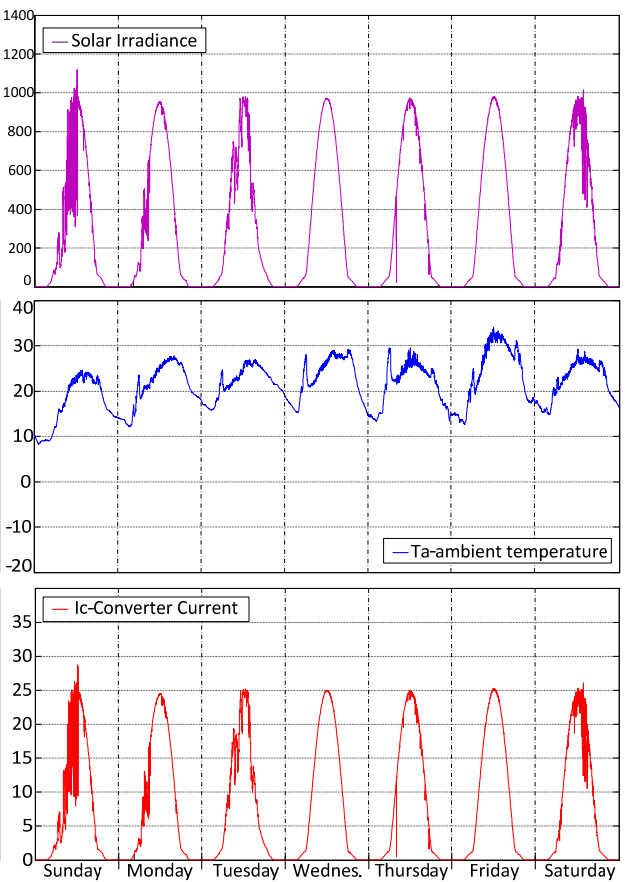

(c) ) One week mission profile during the summer time and the corresponding converter current

Fig. 9. The realistic PV-inverter loading current obtained by using as input in the model a Real Field Mission Profile (SIRR and $\mathrm{T}_{\mathrm{a}}$ ) for one year measurements (a) and one week measurements in winter (b) and in summer period (c)
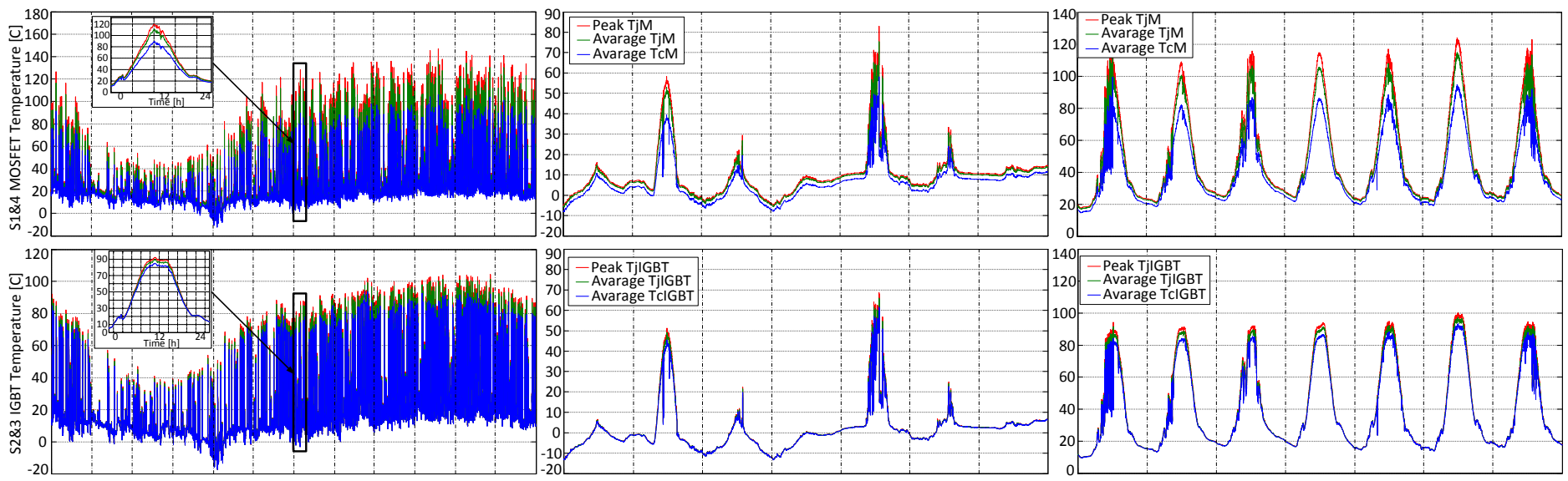

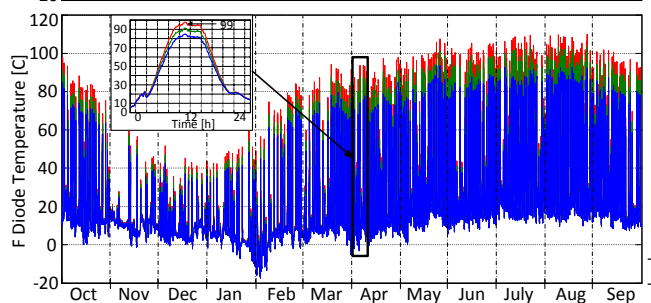

(a)Thermal loading estimation for one year operation

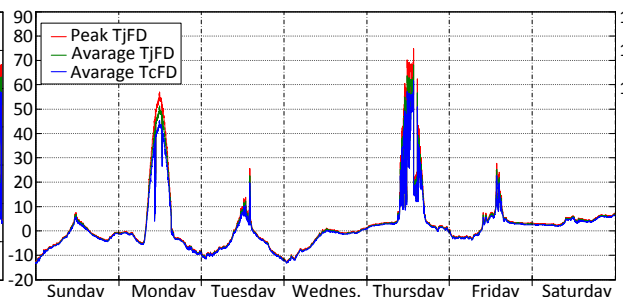

(b) Thermal loading estimation for one week operation during the winter time

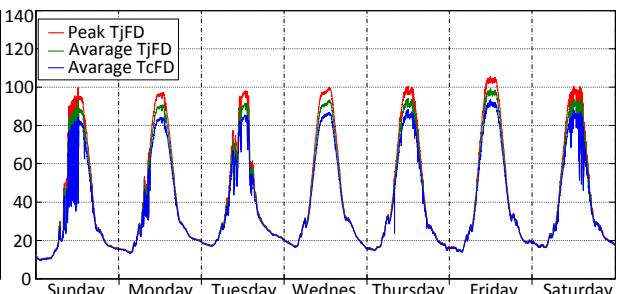

(c) Thermal loading estimation for one week operation during the summer time

Fig. 10. Thermal loading estimation of the 3L-BS NPC PV-inverter devices (MOSFET, IGBT+FD) for one year operation (a), one week operation in the winter time(b) and one week operation in the summer time (c) 
The obtained one year thermal loading distribution among the converter devices (MOSFET, IGBT+FD) in terms of peak junction temperature $\left(\mathrm{T}_{\mathrm{j} \_ \text {peak }}\right)$ and junction temperature variation $\left(\Delta \mathrm{T}_{\mathrm{j}}\right)$ has been used as an input to the evaluation block model seen in Fig. 3. The implemented model relies on the Rainflow algorithm presented in [18]. The main idea of this method is to identify the equivalent full and half cycles within the irregular load profile [18]. The Rainflow cycle counting algorithm is used to analyze the obtained results (from the long term simulation model) in order to perform a thermal loadingbased classification-comparison of the converter devices during one year operation. The obtained results emphasized in Fig. 11, presents the peak junction temperature (Fig. 11 (a)) and the junction temperature variation (Fig. 11 (b)) against the corresponding number of operating cycles. According with Fig. 11 (a), it can be stated that the MOSFET device is operating mostly in a higher temperature range comparing with the IGBT and the FD. The maximum temperature during the operation is $132^{\circ} \mathrm{C}$ for MOSFET, $108.5^{\circ} \mathrm{C}$ for FD and $103.5^{\circ} \mathrm{C}$ for IGBT. Fig. 11 (b) shows the results when the same analyze procedure has been performed for the converter devices by considering as input the junction temperature variation. Also in this case the MOSFET is the most stressed device, in terms of $\Delta \mathrm{T}_{\mathrm{j}}$, followed by the FD and by the IGBT. The maximum junction temperature variation during the operation is $14.3^{\circ} \mathrm{C}$ for MOSFET, $11.8^{\circ} \mathrm{C}$ for FD and $5.2^{\circ} \mathrm{C}$ for IGBT. Analyzing the results provided in Fig. 11, a thermal loading-based classification of the PV-inverter devices, starting with the most stressed one, is given in the following order: MOSFET thermal loading $>$ IGBT thermal loading $>$ FD thermal loading.

Finally it can be stated that the converter is operating in the safe operating area range during the whole year operation.

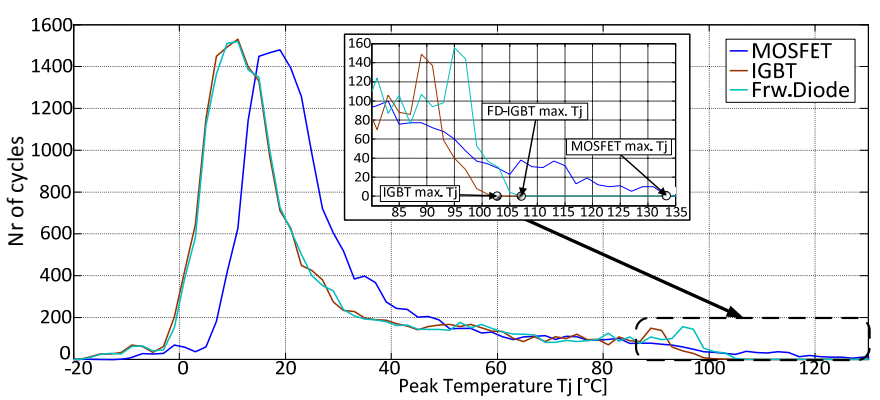

(a) Peak $\mathrm{Tj}$ thermal cycling

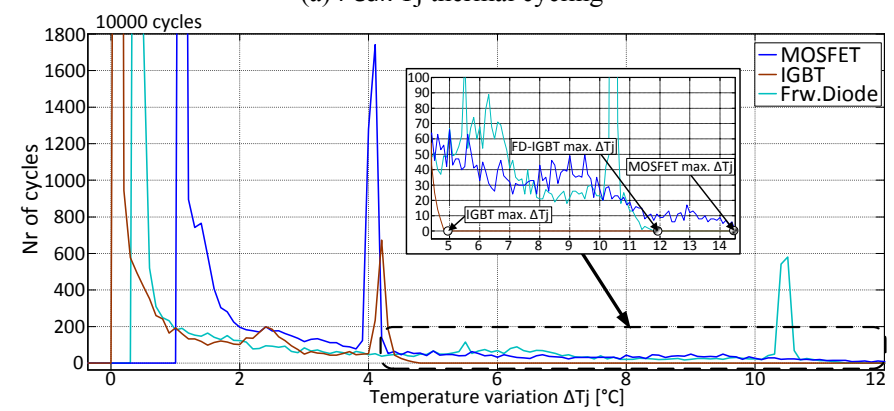

(b) $\Delta \mathrm{Tj}$ thermal cycling variation

Fig. 11. Rainflow Histogram of PV-inverter devices in terms of peak junction temperature (a) and junction temperature variation (b) during one year operation

\section{CONCLUSIONS}

A real field mission profile oriented design for the new generation of grid connected PV-inverters applications has been implemented. The proposed design tool consists of a grid connected PV-inverter model, an Electro-Thermal model, a converter safe operating area (SOA) model, a mission profile model and the evaluation block. Firstly, the detailed design and modeling of a three phase grid connected 3L-BS NPC PVinverter application has been performed. Moreover, a novel Electro-Thermal Model for the new generation of power electronics SiC-devices, has been implemented. Applying the Electro-Thermal model in the PV-inverter application, a SOA model has been developed, in order to calculate the required converter heatsink thermal impedance to perform in a safe mode for the whole operating range. Afterwards, an accurate long term simulation model has been proposed in order to consider the mission profile of the real field where the converter is operating. A mission profile model has been built based on one year measured solar irradiance and ambient temperature at Aalborg University (Denmark) from October 2011 to September 2012. The model predicts the thermal loading repartition within the converter devices, by estimating their junction and case temperature. Moreover the heatsink time response is also considered into the model. Three different cases have been simulated according with the mission profile considered into the proposed design tool. In the first case a one year mission profile with a sampling rate of 5 minutes, has been used into the model. For the second and third case a more detailed analysis has been performed for one week mission profile (in the winter-summer time) with a sampling rate of $25 \mathrm{~s}$ (equal with the heatsink time response).

The simulation results present the load current of the converter due to the real field mission profile applied as an input to the model for all three cases. Moreover, the thermal loading distribution among the converter devices (MOSFET, IGBT+FD) in terms of junction (average and peak) and case (average) temperature for all three simulation cases have been obtained.

It can be concluded that the most stressed device is the MOSFET, followed by the freewheeling diode and finally by the IGBT. The results obtained indicate that the thermal limitations of the devices are not exceeded. Therefore the converter is performing in the safe operating area range for the whole year operation. 


\section{REFERENCES}

[1] B. Ozpineci and L.M. Tolbert, "Comparison of Wide-Bandgap semiconductors for Power Electronics Applications", US Department of Energy-Oak Ridge National Laboratory, December 12,2003.

[2] B.J. Baliga, Silicon Carbide Power Devices, World Scientific Publishing Co. Pte. Ltd. 2006.

[3] G. Deboy, R Rupp Infineon Technologies Austria/Germany, and R. Mallwitz, H. Ludwing, SMA Solar Technology Germany "New SiC JFET Boost Performance of Solar Inverters", Issue 4 Power Electronics Europe 2011.

[4] The Solar Power Magazine-Photon International, July 2012.

[5] H. Wang, K. Ma and F. Blaabjerg, "Design for Reliability of Power Electronic Systems", $38^{\text {th }}$ IEEE International Conference on Industrial Electronics (IECON), pp. 33-44, 2012.

[6] S.E. De Leon-Aldaco, H. Calleja, F. Chan, H.R. Jimenez-Grajales, "Effect of the mission profile on the reliability of a power converter aimed at photovoltaic applications - a case study", IEEE Trans. Power Electron. vol. 28 no. 6, pp. 2998-3007, June 2013.

[7] L.M. Moore and H.N. Post, "Five years of operating experience at a large, utility-scale photovoltaic generating plant", Journal of Prog. Photovolt: Res. Appl. vol. 16 no. 3, pp. 249-259, 2008.

[8] S. Yang, D. Xiang, A. Briant, P. Mawby, L. Ran and P. Tavner, "Condition Monitoring for Device Reliability in Power Electronic Converters: A Review", IEEE Transactions on Power Electronics, Vol. 25, pp. 2734-2752, Nov. 2010.

[9] ZVEL, Handbook for Robustness validation of automotive electrical/electronic modules, June 2008.

[10] E. Wolfgang, "Examples of failures in power electronics systems", ECPE Tutorial-Reliability of Power Electronics Systems, Nuremberg, Germany, April 2007.

[11] F. Chan, and H. Calleja, "Reliability estimation of three single-phase topologies in grid-connected PV systems", IEEE Trans. Ind. Electron. vol. 58 no. 7, pp. 2683-2689, July 2011.

[12] G. Petrone, G. Spagnuolo, R. Teodorescu, M. Veerachary, and M. Vitelli, "Reliability issues in photovoltaic power processing systems", IEEE Trans. Ind. Electron. vol. 55 no. 7, pp. 2569-2580, July 2008.

[13] F. Blaabjerg, K. Ma and D. Zhou, "Power electronics and reliability in renewable energy systems", IEEE International Symposium on Industrial Electronics (ISIE), pp. 19-30, July 2012.

[14] T. Brückner and S. Bernet, "Estimation and Measurement of Junction Temperatures in a Three-Level Voltage Source Converter", IEEE Industry Applications Conference IAS Annual Meeting 2005, pp. 106114.

[15] Y. Xue, K.C. Divya, G. Griepentrog, M. Liviu, S. Suresh, and M Manjrekar, "Towards next generation photovoltaic inverters", IEEE ECCE, pp. 2467-2474, 2011.

[16] C. Sintamarean and F. Blaabjerg, "Comprehensive Evaluation on Efficiency and Thermal Loading of Associated Si and SiC based PV Inverter Applications", IECON ,November 2013.

[17] C. Sintamarean, F. Blaabjerg, and H. Wang, "A Novel Electro-Thermal Model for Wide Bandgap WBG-semiconductor based devices", IEEE European Conference on Power Electronics and Applications, EPE ECCE Europe, September 2013

[18] M. Musallam, and C. Johnson, "An Efficient Implementation of the Rainflow Counting Algorithm for Life Consumption Estimation”, IEEE Trans. on Reliability, Vol. 61, No. 4, pp. 978-986, December 2012. 